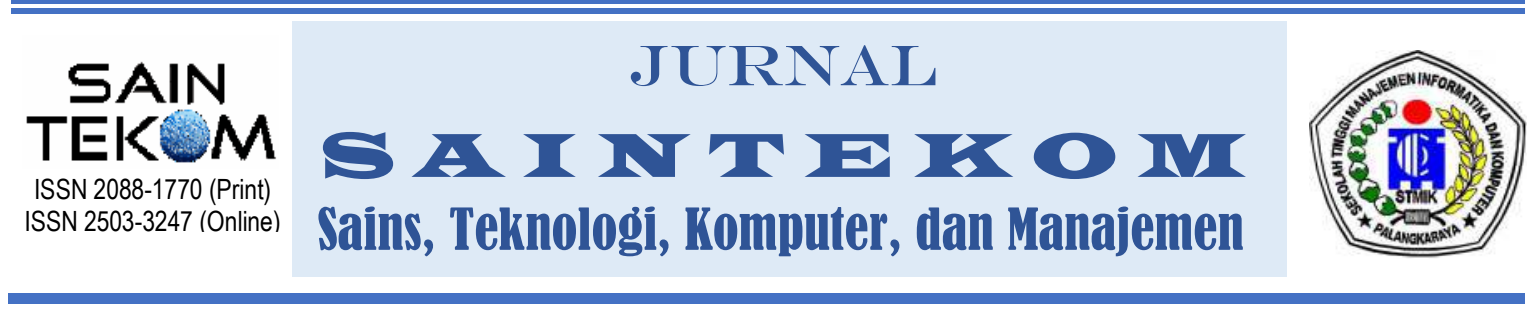

\title{
PENENTUAN POLA PEMBELIAN OBAT MENGGUNAKAN ALGORITMA APRIORI
}

\author{
*Moch. Syahrir ${ }^{1}$, Ria Rismayanti ${ }^{2}$, Moh. Arief Wicaksono ${ }^{3}$ \\ 1,2,3)Program Studi Ilmu Komputer Universitas Bumigora \\ Jl.Ismail Marjuki No 22 Cakranegara Kota Mataram-NTB \\ Email: muhammadsyahriralfath@gmail.com, riris@universitasbumigora.ac.id, \\ ariefw162@gmail.com
}

\begin{abstract}
Pharmacy is one of the businesses engaged in the health sector, especially product and services in improving public health. This service is carried out by a pharmacy manager in an effort to fulfill the duties and functions of pharmacy. This causes problems that occur in pharmacies, when search for drugs must be done by looking for one by one in transaction, because the pharmacy manager does not know sure the stock of drugs in the pharmacy. In addition, another problem is the arrangement of irregular drug layouts where the drug placement does not have a good standard layout. The method used in building this system is association with a priori on sales transaction data. then processed in a model to explore valuable information, as a policy standard in running a business. Application testing uses 3 minimum support and confidence values so can get the rule and k-Itemset results from 3 different values.
\end{abstract}

Keyword : Pattern Determination, Association Method, Apriori Algorithm.

\section{ABSTRAK}

Apotek merupakan salah satu usaha yang bergerak di bidang kesehatan khususnya pelayanan produk dan jasa dalam meningkatkan kesehatan masyarakat. Pelayanan ini dilakukan oleh seorang pengelola apotek dalam upaya memenuhi tugas dan fungsi apotek.. Hal ini menyebabkan adanya permasalahan yang terjadi diapotek yaitu dalam pencarian obat harus dilakukan dengan mencari satu persatu dalam buku transaksi penjualan, karena pengelola apotek tidak mengetahui secara pasti stok obat yang ada di apotek. Selain itu permasalahan lainnya adalah pengaturan tata letak obat yang tidak teratur dimana peletakkan obat tidak memiliki standart letak yang baik. Metode yang digunakan dalam membangun sistem ini yaitu asosiasi dengan algoritma apriori berdasarkan data transaksi penjualan. selanjutnya diolah dalam model untuk menggali informasi berharga, sebagai standart kebijakan dalam menjalankan usaha. Pengujian aplikasi menggunakan 3 nilai minimum support maupun minimum confidence agar nantinya bisa mendapatkan hasil rule dan $k$-Itemset dari ke 3 nilai yang berbeda.

Kata kunci : Penentuan Pola, Metode Asosiasi, Algoritma Apriori. 


\section{PENDAHULUAN}

Perkembangan teknologi yang semakin pesat memberikan dampak yang sangat signifikan dalam berbagai bidang. Tak terkecuali dalam bidang bisnis jual beli khususnya apotek yang semakin hari semakin tingginya persaingan antara pengusaha. Banyak hal yang dilakukan pelaku usaha apotek untuk menghadapi persaingan pada era teknologi seperti saat ini (Putra et al., 2019). Pemanfaatan teknologi informasi dalam mendukung aktifitas usaha apotek juga semakin maju dan berkembang. Para pelaku usaha memanfaatkan hal ini untuk meningkatkan strategi-strategi bisnis mereka. Pemanfaatan data yang dikelola kerap menjadi objek dalam memberikan informasi untuk meningkatkan kualitas dan efektif dalam kegiatan usaha jual beli (Syahrir and Fatimatuzzahra, 2020).

Kemudahan dalam pengelolaan data yang menjadi objek dalam menggali informasi-informasi baru yang mendukung pengetahuan pelaku usaha apotek dalam meningkatkan strategi bisnis tersebut dilakukan dengan menggunakan teknik data mining. Hal terpenting dalam teknik data mining adalah aturan untuk menemukan pola frekuensi tinggi antar himpunan itemset yang disebut fungsi association rule (aturan asosiasi) (Efendi, 2019) (Grand, 2018). Proses pencarian asosiasi atau hubungan antar item data ini diambil dari suatu basis data relasional. Proses tersebut menggunakan algoritma apriori. Munculnya data mining didasarkan pada kenyataan bahwa jumlah data yang tersimpan dalam basis data semakin besar (Gibran and Aripin, 2016) (Tiarapuspa et al., 2020). Untuk data yang semakin bertambah jumlahnya dari waktu kewaktu menyebabkan munculnya pertanyaan yakni untuk apa data-data tersebut, tentu menjadi hal yang sia-sia jika data tersebut tidak dimanfaatkan untuk kepentingan perusahaan atau instansi itu sendiri dalam persaingan di dunia usaha, di tuntut untuk menemukan suatu strategi tepat yang dapat digunakan dalam penjualan (Jayapana and Rahayu, 2015).

Salah satu strategi dalam optimasi adalah dengan penentuan tata letak obat yang akan membantu mempermudah dan mempercepat 
kinerja karyawan dalam melakukan pelayanan kepada konsumen, selain itu dengan menjaga persediaan obat tetap tersedia.

Dalam penelitian ini penulis mengambil studi kasus di Apotek karunia montong gamang lombok tengah, dengan mengunakan data transaksi sebagai objek yang akan diolah dengan sebuah aplikasi data mining yang dibangun menggunakan algoritma apriori. algoritma ini untuk menghasilkan pola kombinasi item pembelian konsumen apotek karunia montong gamang lombok tengah sebagai acuan untuk mengambil suatu kebijakan.

\section{METODE}

Diagram alir penelitian bisa di lihat pada gambar 1 .

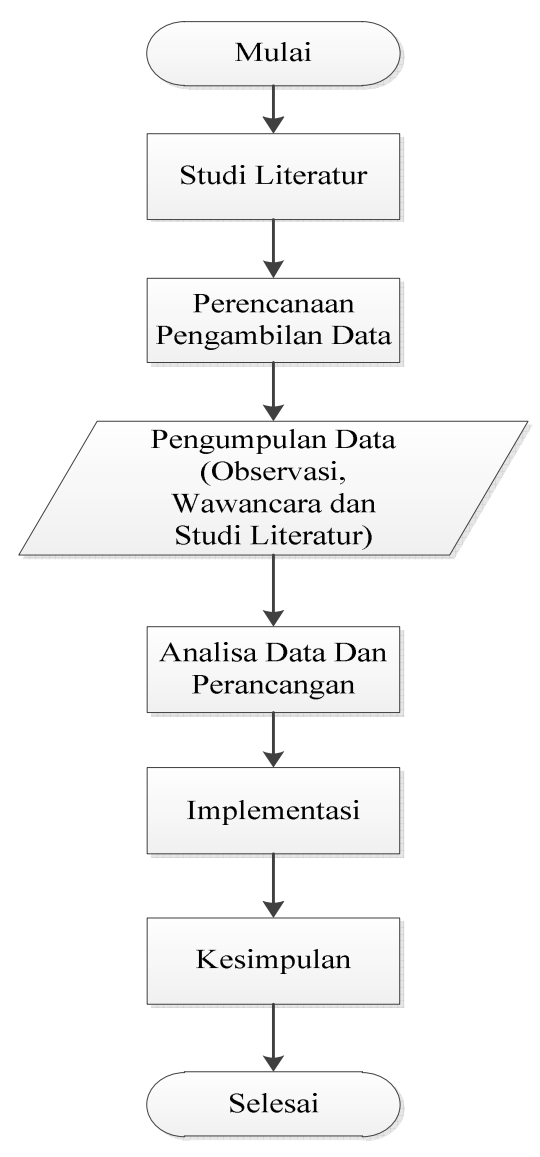

Gambar 1 Diagram Alir Penelitian

\subsection{Metode Pengumpulan Data}

Metode pengumpulan data yang penulis gunakan pada penelitian ini sebagai berikut:

a. Observasi

Proses observasi di lakukan dengan mengamati langsung proses pengolahan data transaksi pada tempat penelitian serta membuatkan beberapa dokumentasi untuk keperluan data-data yang akan di olah nantinya. Observasi merupakan cara pengumpulan data 
yang dilakukan secara sistematis dan sengaja, yang dilakukan melalui pengamatan dan pencatatan gejala-gejala yang diselidiki dengan menggunakan alat indra terutama mata terhadap kejadian yang sedang berlangsung (Hasanah, 2017).

b. Wawancara

Wawancara yang dilakukan yaitu tanya jawab antara peneliti dan narasumber dengan tujuan untuk menggali data atau memperoleh informasi yang berhubungan dengan penelitian. Tahap ini penulis langsung mewawancarai langsung pemilik dan karyawan yang berkaitan dengan kendalakendala lapangan dan di lakukan pencatatan.

c. Literatur

Sumber literatur banyak di dapatkan artikel atau jurnal, karya ilmiah, dan situs-situs penunjang, seperti contoh, disini penulis mengambil literature dari buku “Data Mining The Textbook' oleh (Aggarwal, 2015). Sementara beberapa artikel yang langsung penulis gunakan sebagai referensi dan daftar pustaka.

\subsection{Analisis dan Perancangan Sistem}

a. Analisis Sistem

Tujuan dari analisis ini adalah untuk membantu mengetahui masalah yang ada dan merancang model suatu sistem yang akan dibangun sehingga menjadi tepat guna (M. Afdal and Rosadi, 2019) (Hasan et al., 2019). Penelitian ini akan menghasilkan suatu website yang mampu mengolah data transaksi penjualan obat di apotek, yang mana outputnya adalah rule atau aturan asosiasi.

b. Analisis Masalah

Masalah yang diangkat dalam penelitian ini adalah bagaimana cara menentukan pola pembelian obat pada apotek yang akan menggunakan algoritma apriori untuk mendapatkan informasi, dimana dalam transaksi pembelian produk akan dilihat dari kecendurungan pembelian obat yang sering dibeli oleh konsumen (Jayapana and Rahayu, 2015). Dengan mengetahui informasi kombinasi pembelian tersebut 
pemilik apotek dapat menganalisa penyediaan barang maupun pengaturan letak barang sesuai kombinasi. Adapun data mentah yang digunakan dari tempat penelitian dapat pada tabel 1 .

Tabel 1 Transaksi Pembelian Obat

\begin{tabular}{|c|c|c|}
\hline No & Tanggal & Nama Obat \\
\hline 1. & $18 / 3 / 2019$ & $\begin{array}{l}\text { Antangin,Gazero, Promag, } \\
\text { Cair,OBH Combi, } \\
\text { Novamox,Masker,Tespek, } \\
\text { Vitacimin,Yusimox }\end{array}$ \\
\hline 2. & $19 / 3 / 2019$ & $\begin{array}{l}\text { Gom, Vitacimin, Biolysin } \\
\text { Smart, Kapas 25gr, Bedak } \\
\text { Salicyl }\end{array}$ \\
\hline 3. & $20 / 3 / 2019$ & $\begin{array}{l}\text { Vitacimin, Insto, Solinfee, } \\
\text { Wiros, Vipcol, Yusimox, } \\
\text { Novamox, Baby Cough, } \\
\text { Coparcetin, Promag, } \\
\text { Bioplacenton, Hansaplas } \\
\text { Rol, Rohto, Caviplex, } \\
\text { Gratheos, Hufagrip, } \\
\text { Tespek }\end{array}$ \\
\hline 4. & $21 / 3 / 2019$ & $\begin{array}{l}\text { Pil Kita, Gratheos, } \\
\text { Amoxillin, Dehista, } \\
\text { Coparcetin, Piroxicam, } \\
\text { Dexaharsen, Ranitidine, } \\
\text { Solinfec, Etambroxol, } \\
\text { Fasidol Forte, Dulcolax, } \\
\text { Fargetix }\end{array}$ \\
\hline 5. & $22 / 3 / 2019$ & $\begin{array}{l}\text { Oralit, Sangobion, } \\
\text { Paracetamol, Insto, } \\
\text { Betasone, Kapsida, } \\
\text { Demacolin }\end{array}$ \\
\hline 6. & $23 / 3 / 2019$ & $\begin{array}{l}\text { Paracetamol, Yusimox, } \\
\text { Kapas Nasaco, Balsem } \\
\text { Lang,Baraito ,Antangin, } \\
\text { Amoxcillin, Vitacimin, } \\
\text { Mycoral, Kapsa, Masker, } \\
\text { Farsifen, Dexaharsen, } \\
\text { Dexometasone, } \\
\text { Coparcetin, Caviplex }\end{array}$ \\
\hline 7. & $24 / 3 / 2019$ & $\begin{array}{l}\text { Amoxcillin, Paracetamol, } \\
\text { Vitacimin, Caviplex, } \\
\text { Bodrexin, Bodrex, } \\
\text { Mixagrip, Sutra Hitam, } \\
\text { Proris, Demacolin, } \\
\text { Sanmol, Herocyn, } \\
\text { Vitaquin, Broncitin, PCT, }\end{array}$ \\
\hline
\end{tabular}

\begin{tabular}{|c|c|c|}
\hline No & Tanggal & Nama Obat \\
\hline & & Coldrexin \\
\hline 8. & $25 / 3 / 2019$ & $\begin{array}{l}\text { Oralit, Antangin, } \\
\text { Sangobion, Minyak Kayu } \\
\text { Putih, Telon Lang, } \\
\text { Mycoral, Woods, } \\
\text { Hufagrip }\end{array}$ \\
\hline 9. & $26 / 3 / 2019$ & $\begin{array}{l}\text { Imunos, Wiros, Fasidol } \\
\text { Forte, Fargetik, } \\
\text { Dexaharsen, Madu Tj, } \\
\text { Vitacimin, Tolak Angin, } \\
\text { Etamoxul, Griseofalvin, } \\
\text { Solinfec, PCT, Vicks } \\
\text { Formula 44, Vicks } \\
\text { Formula } 44 \text { Anak, } \\
\text { Handsloond }\end{array}$ \\
\hline 10. & $27 / 3 / 2019$ & $\begin{array}{l}\text { Imunos,Tera-F, } \\
\text { Bronchitin, Iclitiol, } \\
\text { Griseofalvin, } \\
\text { Kentoconazole, Balsem } \\
\text { Otot Geliga, Masker, } \\
\text { Madu Tj, Guanistrep, } \\
\text { Rhemafar, Dexaharsen }\end{array}$ \\
\hline 11. & $28 / 3 / 2019$ & $\begin{array}{l}\text { Antangin, Parfum, } \\
\text { Imunos, Masker, } \\
\text { Dehista,Vitacimin, } \\
\text { Tespek, Solinfec, Sanmol, } \\
\text { Captopril, }\end{array}$ \\
\hline
\end{tabular}

Data dalam tabel 1 adalah data transaksi penjualan obat di apotik yang di ambil pada tahun 2019 sebagai sample data sebelum melakukan pengolahan pada tahap model. Untuk mendapatkan aturan asosiasi algoritma apriori memiliki standart penilaian berupa support, confidence, dan lift rasio. Adapun rumus yang digunakan seperti pada rumus $(1)(2)(3)$.

$$
\begin{aligned}
& \text { Support }(\mathbf{X} \rightarrow \mathbf{Y})=\frac{\sigma[X \cup Y}{N} \\
& \text { Confidence }(\mathbf{X} \rightarrow \mathbf{Y})=\frac{\sigma[X \cup Y]}{X} \\
& \text { Lift Rasio }(\mathrm{X} \rightarrow \mathrm{Y})=\frac{\sigma[X \cup Y]}{\sigma(X) * \sigma(\mathbf{Y}]}
\end{aligned}
$$


Keterangan :

Kekuatan aturan asosiasi dapat di ukur dengan support, confidence, dan lift rasio. Support menentukan seberapa sering aturan tersebut diterapkan dalam dataset. Confidence menentukan frekuensi item dalam $\mathrm{Y}$ mucul dalam transaksi yang mengandung $\mathrm{X}$, sementara lift ratio untuk mengukur besarnya hubungan antara antecedent dan consequent, lift rasio memiliki range nilai dari 0 sampai tidak terhingga. Nilai yang mendekati 1 mengindikasikan bahwa antecedent dan consequent tidak memiliki ketergantungan sementara yang jauh dari 1 maka sebaliknya (Aggarwal, 2015). Adapun alur dari tahapan algoritma apriroi dapat dilihat pada gambar 2.

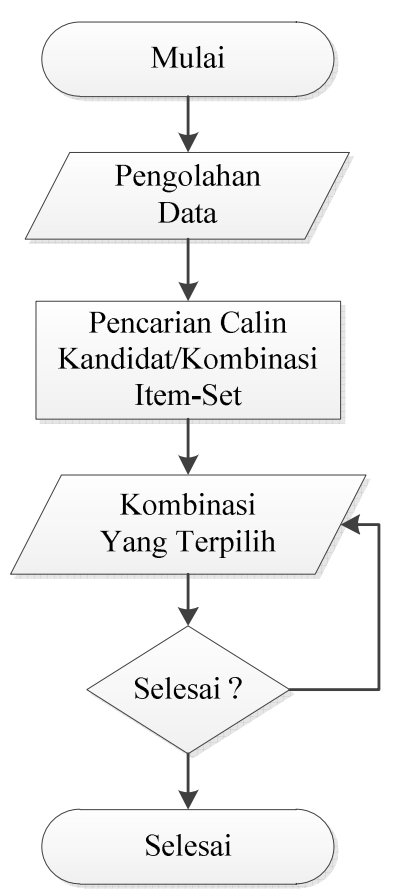

Gambar 2 Diagram Alir Tahapan Apriori

Gambar 2 menunjukkan diagram alir dari tahapan apriori. Tahapan ini dimulai dari proses pengolahan data, kemudian dilanjutkan dengan pencarian calon kombinasi itemset untuk menemukan kombinasi yang terpilih namun jika tidak menemukan kombinasi terpilih maka akan terus melakukan proses pencarian kombinasi.

c. Analisis Kebutuhan Sistem

1) Kebutuhan Fungsional

Kebutuhan fungsional yang dibutuhkan dalam membangun sistem dapat dilihat pada tabel 2 :

Tabel 2 Kebutuhan Fungsional

\begin{tabular}{|c|c|}
\hline Kebutuhan & \multicolumn{2}{|c|}{ Keterangan } \\
\hline Admin & $\begin{array}{l}\text { 1. Melakukan login admin } \\
\text { kedalam sistem. }\end{array}$ \\
\hline
\end{tabular}




\begin{tabular}{|c|c|}
\hline Kebutuhan & Keterangan \\
\hline & $\begin{array}{l}\text { 2. Menampilkan halaman } \\
\text { utama. } \\
\text { 3. Import atau masukan data } \\
\text { transaksi penjualan obat } \\
\text { dengan format.csv } \\
\text { 4. Mengelola Data Testing } \\
\text { (tentukan dan input nilai } \\
\text { minimum support dan } \\
\text { minimum confidence } \\
\text { 5. Menampilkan hasil } \\
\text { algoritma apriori dan hasil } \\
\text { aturan asosiasi } \\
\text { 6. Melakukan logout }\end{array}$ \\
\hline
\end{tabular}

Pada Tabel 2 dapat dilihat bahwa pengguna dari sistem ini adalah seorang admin yang mana admin tersebut memiliki kebutuhan fungsional seperti import data, mengelola data dan lain-lain.

2) Kebutuhan Non-Fungsional

Kebutuhan non fungsional berupa kebutuhan hardware dan software yakni kebutuhan perangkat keras (Hardware).

Kebutuhan perangkat keras (Hardware) yang digunakan untuk membangun system ini adalah sebagai berikut:
a. Intel ${ }^{\circledR} \operatorname{core}^{\mathrm{TM}}$ i5-6200u cpu @ 2,30ghz (4cpus), 2,4ghz
b. Ram $4 \mathrm{gb}$
c. Hardisk $512 \mathrm{gb}$ dan ssd $120 \mathrm{gb}$
d. Lcd 14"

Sedangkan untuk kebutuhan perangkat lunaknya adalah sebagai berikut :
a. Sistem Operasi Windows 10 64-bit
b. Bahasa Pemrograman PHP
c. Visual Studio Code
d. Xampp (MySQL)
e. $\quad \operatorname{Star} U M L$
f. Microsoft Excel

\subsection{Perancangan Diagram}

\section{a. Use Case Diagram}

Use Case Diagram merupakan teknik pemodelan untuk menjelaskan setiap aktivitas yang mungkin terjadi dengan menggunakan sudut pandang aktor utama admin sebagai pengguna sistem. Gambaran use case diagram yang digunakan pada aplikasi berbasis web dapat dilihat pada gambar 3 .

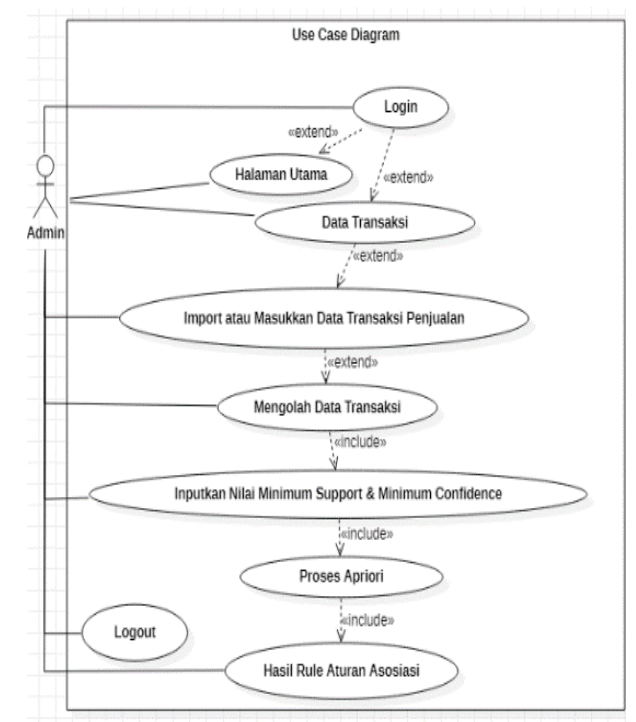

Gambar 3 Use Case Diagram 
Gambar 3 menunjukkan use case diagram dari sistem yang akan dibangun. Pada gambar 3 terdapat seorang aktor yaitu admin yang mana admin tersebut dapat mengolah seluruh sistem mulai dari input manual, import data transaksi penjualan, melakukan proses perhitungan dengan menentukan nilai minimum support dan minimum confidence, melihat hasil perhitungan dan mengganti password akun.

\subsection{Tampilan Aplikasi}

Dalam bagian ini akan di tampilkan beberapa form utama dari aplikasi yang dibangun.

a. Halaman Proses Algoritma Apriori

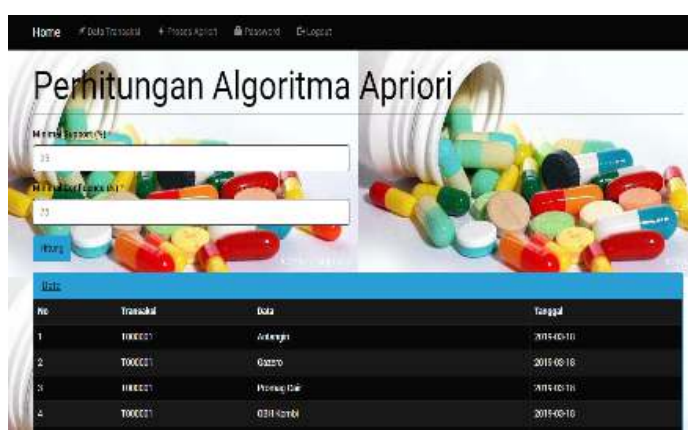

Gambar 4 Proses Algoritma Apriori

Pada gambar 4 kita bisa melihat hasil proses dari algoritma apriori mengolah data untuk mendapatkan informasi. b. Hasil Pembentukan Itemset

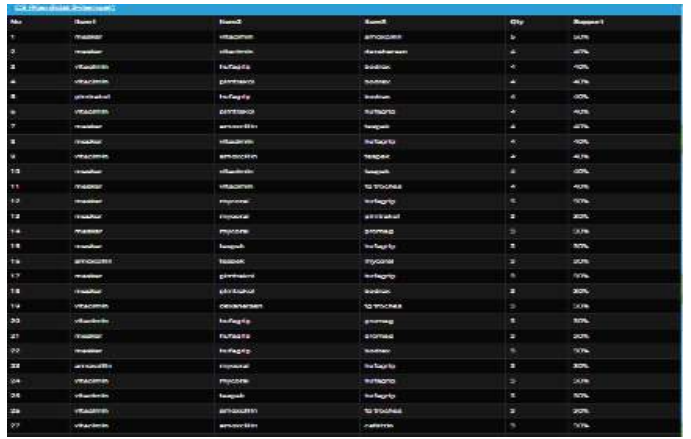

Gambar 5 Pembentukan Itemset

Pada gambar 5 ini kita bisa melihat rule-rule yang terbentuk sebagai acuan tata letak barang, atau media promosi dalam menjual barang bersamaan tetapi dalam satu paket yang sama.

c. Hasil Aturan Asosiasi

Hasil akhir aturan dan rule yang telah terbentuk dengan nilai frekuensi, support, confidence dan lift ratio dapat di lihat pada gambar 6 .

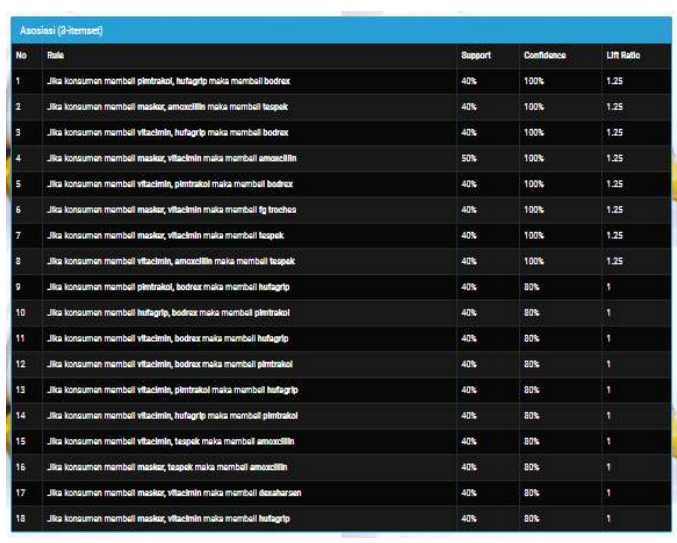

Gambar 6 Gambar Hasil Aturan Asosiasi 


\section{HASIL DAN PEMBAHASAN}

\subsection{Data Transaksi}

Penelitian ini menggunakan data transaksi, yang mana data tersebut dilakukan preprocessing terlebih dahulu untuk mebersihkan data. Adapun data tersebut dapat dilihat pada tabel 3 .

Tabel 3 Data Transaksi

\begin{tabular}{|l|l|l|c|}
\hline id & id_transaksi & \multicolumn{1}{|c|}{ item } & Tanggal \\
\hline 1 & $\mathrm{~T} 000044$ & Masker & $5 / 1 / 2019$ \\
\hline 2 & $\mathrm{~T} 000044$ & Vitacimin & $5 / 1 / 2019$ \\
\hline 3 & $\mathrm{~T} 000044$ & Dexaharsen & $5 / 1 / 2019$ \\
\hline 4 & $\mathrm{~T} 000044$ & Amoxcillin & $5 / 1 / 2019$ \\
\hline 5 & $\mathrm{~T} 000044$ & Fg Troches & $5 / 1 / 2019$ \\
\hline 6 & $\mathrm{~T} 000044$ & Cetirizin & $5 / 1 / 2019$ \\
\hline 7 & $\mathrm{~T} 000044$ & Tespek & $5 / 1 / 2019$ \\
\hline 8 & $\mathrm{~T} 000045$ & Masker & $5 / 2 / 2019$ \\
\hline 9 & $\mathrm{~T} 000045$ & Mycoral & $5 / 2 / 2019$ \\
\hline 10 & $\mathrm{~T} 000045$ & Pimtrakol & $5 / 2 / 2019$ \\
\hline 11 & $\mathrm{~T} 000045$ & Licofel & $5 / 2 / 2019$ \\
\hline 12 & $\mathrm{~T} 000045$ & Wiros & $5 / 2 / 2019$ \\
\hline 13 & $\mathrm{~T} 000045$ & Livron & $5 / 2 / 2019$ \\
\hline 14 & $\mathrm{~T} 000045$ & Molacort & $5 / 2 / 2019$ \\
\hline 15 & $\mathrm{~T} 000045$ & Strepsil & $5 / 2 / 2019$ \\
\hline 16 & $\mathrm{~T} 000045$ & Sanmol & $5 / 2 / 2019$ \\
\hline 17 & $\mathrm{~T} 000046$ & Masker & $5 / 3 / 2019$ \\
\hline 18 & $\mathrm{~T} 000046$ & Vitacimin & $5 / 3 / 2019$ \\
\hline 19 & $\mathrm{~T} 000046$ & Mycoral & $5 / 3 / 2019$ \\
\hline 20 & $\mathrm{~T} 000046$ & Hufagrip & $5 / 3 / 2019$ \\
\hline
\end{tabular}

\subsection{Tabel Tabular}

Salah satu tahapan algoritma apriori yang membentuk tabel tabular untuk mempermudah pencarian frekuensi itemset dan menghitung jumlah frekuensi. Adapun hasil dari data pada tabel 3 yang sudah dikonversi ke tabularnya dapat dilihat pada Gambar 7.
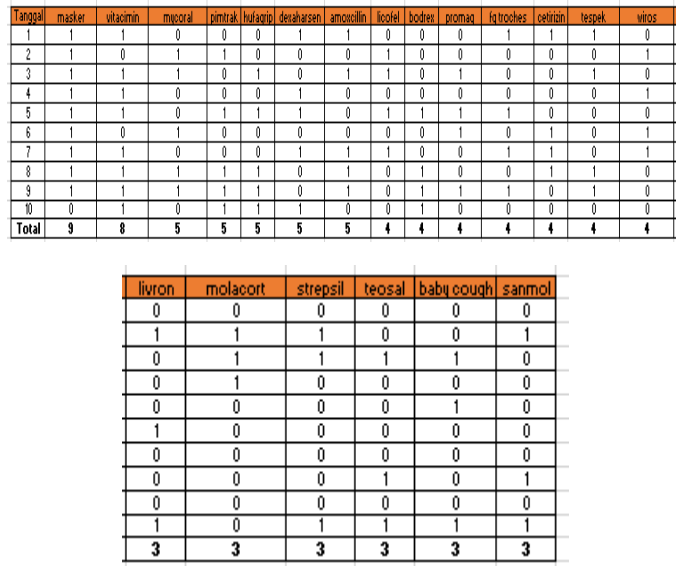

Gambar 7 Tabel Tabular

\subsection{Perhitungan Manual}

a. Pencarian Itemset

Berikut proses yang dilakukan yaitu menentukan itemset 1 dengan persamaan (1),(2),(3) dengan data seperti pada tabel 4 dibawah ini:

Tabel 4 Pembentukan 1 Itemset

\begin{tabular}{|c|l|c|c|}
\hline No & \multicolumn{1}{|c|}{ Item1 } & Qty & Support \\
\hline 1 & Masker & 9 & $90 \%$ \\
\hline 2 & Vitacimin & 8 & $80 \%$ \\
\hline 3 & Pimtrakol & 5 & $50 \%$ \\
\hline 4 & Dexaharsen & 5 & $50 \%$ \\
\hline 5 & Amoxcillin & 5 & $50 \%$ \\
\hline 6 & Hufagrip & 5 & $50 \%$ \\
\hline 7 & Mycoral & 5 & $50 \%$ \\
\hline 8 & Promag & 4 & $40 \%$ \\
\hline 9 & Wiros & 4 & $40 \%$ \\
\hline 10 & Licofel & 4 & $40 \%$ \\
\hline 11 & Tespek & 4 & $40 \%$ \\
\hline 12 & Cetirizin & 4 & $40 \%$ \\
\hline 13 & Fg troches & 4 & $40 \%$ \\
\hline 14 & Bodrex & 4 & $40 \%$ \\
\hline
\end{tabular}

b. Pembentukan Aturan Asosiasi

Tabel 5 Pembentukan Aturan Asosiasi

\begin{tabular}{|c|c|c|c|c|}
\hline No & Rule & Sup & Conf & $\begin{array}{c}\text { Lift } \\
\text { Ratio }\end{array}$ \\
\hline 1 & $\begin{array}{l}\text { Jika konsumen } \\
\text { membeli pimtrak } \\
\text { ol, hufagrip maka }\end{array}$ & $40 \%$ & $100 \%$ & 1.25 \\
\hline
\end{tabular}

Jurnal Saintekom, Vol.11, No.2, September 2021 


\begin{tabular}{|c|c|c|c|c|}
\hline No & Rule & Sup & Conf & $\begin{array}{c}\text { Lift } \\
\text { Ratio }\end{array}$ \\
\hline & membeli bodrex & & & \\
\hline 2 & $\begin{array}{l}\text { Jika konsumen } \\
\text { membeli masker, } \\
\text { amoxcillin maka } \\
\text { membeli tespek }\end{array}$ & $40 \%$ & $100 \%$ & 1.25 \\
\hline 3 & $\begin{array}{l}\text { Jika konsumen } \\
\text { membeli vitacimi } \\
\text { n, hufagrip maka } \\
\text { membeli bodrex }\end{array}$ & $40 \%$ & $100 \%$ & 1.25 \\
\hline 4 & $\begin{array}{l}\text { Jika konsumen } \\
\text { membeli masker, } \\
\text { vitacimin maka } \\
\text { membeli amoxcill } \\
\text { in }\end{array}$ & $50 \%$ & $100 \%$ & 1.25 \\
\hline 5 & $\begin{array}{l}\text { Jika konsumen } \\
\text { membeli vitacimi } \\
\text { n, } \\
\text { pimtrakol maka } \\
\text { membeli bodrex }\end{array}$ & $40 \%$ & $100 \%$ & 1.25 \\
\hline 6 & $\begin{array}{l}\text { Jika konsumen } \\
\text { membeli masker, } \\
\text { vitacimin maka } \\
\text { membeli fg } \\
\text { troches }\end{array}$ & $40 \%$ & $100 \%$ & 1.25 \\
\hline 7 & $\begin{array}{l}\text { Jika konsumen } \\
\text { membeli masker, } \\
\text { vitacimin maka } \\
\text { membeli tespek }\end{array}$ & $40 \%$ & $100 \%$ & 1.25 \\
\hline 8 & $\begin{array}{l}\text { Jika konsumen } \\
\text { membeli vitacimi } \\
\text { n, } \\
\text { amoxcillin maka } \\
\text { membeli tespek }\end{array}$ & $40 \%$ & $100 \%$ & 1.25 \\
\hline 9 & $\begin{array}{l}\text { Jika konsumen } \\
\text { membeli pimtrak } \\
\text { ol, bodrex maka } \\
\text { membeli hufagrip }\end{array}$ & $40 \%$ & $80 \%$ & 1 \\
\hline 10 & $\begin{array}{l}\text { Jika konsumen } \\
\text { membeli hufagrip } \\
\text {, bodrex maka } \\
\text { membeli pimtrak } \\
\text { ol }\end{array}$ & $40 \%$ & $80 \%$ & 1 \\
\hline 11 & $\begin{array}{l}\text { Jika konsumen } \\
\text { membeli vitacimi } \\
\mathrm{n} \text {, bodrex maka } \\
\text { membeli hufagrip }\end{array}$ & $40 \%$ & $80 \%$ & 1 \\
\hline 12 & $\begin{array}{l}\text { Jika konsumen } \\
\text { membeli vitacimi } \\
\mathrm{n} \text {, bodrex maka } \\
\text { membeli pimtrak } \\
\text { ol }\end{array}$ & $40 \%$ & $80 \%$ & 1 \\
\hline 13 & $\begin{array}{l}\text { Jika konsumen } \\
\text { membeli vitacimi } \\
\text { n, } \\
\text { pimtrakol maka } \\
\text { membeli hufagrip }\end{array}$ & $40 \%$ & $80 \%$ & 1 \\
\hline 14 & $\begin{array}{l}\text { Jika konsumen } \\
\text { membeli vitacimi }\end{array}$ & $40 \%$ & $80 \%$ & 1 \\
\hline
\end{tabular}

\begin{tabular}{|c|c|c|c|c|}
\hline No & Rule & Sup & Conf & $\begin{array}{c}\text { Lift } \\
\text { Ratio }\end{array}$ \\
\hline & $\begin{array}{l}\text { n, hufagrip maka } \\
\text { membeli pimtrak } \\
\text { ol }\end{array}$ & & & \\
\hline 15 & $\begin{array}{l}\text { Jika konsumen } \\
\text { membeli vitacimi } \\
\mathrm{n} \text {, tespek maka } \\
\text { membeli amoxcill } \\
\text { in }\end{array}$ & $40 \%$ & $80 \%$ & 1 \\
\hline 16 & $\begin{array}{l}\text { Jika konsumen } \\
\text { membeli masker, } \\
\text { tespek maka } \\
\text { membeli amoxcill } \\
\text { in }\end{array}$ & $40 \%$ & $80 \%$ & 1 \\
\hline 17 & $\begin{array}{l}\text { Jika konsumen } \\
\text { membeli masker, } \\
\text { vitacimin maka } \\
\text { membeli dexahar } \\
\text { sen }\end{array}$ & $40 \%$ & $80 \%$ & 1 \\
\hline 18 & $\begin{array}{l}\text { Jika konsumen } \\
\text { membeli masker, } \\
\text { vitacimin maka } \\
\text { membeli hufagrip }\end{array}$ & $40 \%$ & $80 \%$ & 1 \\
\hline
\end{tabular}

\subsection{Hasil Evaluasi}

Untuk rule yang dihasilkan dapat diketahui yaitu dengan perbandingan nilai minimum support $30 \%$ dan minimum confidence $80 \%$, minimum support $40 \%$ dan minimum confidence $80 \%$, minimum support $35 \%$ dan minimum confidence $60 \%$ sebagai berikut :

a. Rule Minimum Support 30\% dan Minimum Confidence 80\% Untuk rule yang dihasilkan pada minimum support $30 \%$ dan minimum confidence $80 \%$ disini menghasilkan 20 rule dengan lift ratio 1 sampai 1,25 hasil ini akan kita bandingkan dengan nilai 
minimum support dan minimum confidence selanjutnya.

b. Rule Minimum Support $40 \%$ dan Minimum Confidence 80\%

Untuk rule yang dihasilkan pada minimum support $40 \%$ dan minimum confidence $80 \%$ disini menghasilkan 18 rule dengan lift ratio 1 sampai 1,25 hasil ini akan kita bandingkan dengan nilai minimum support dan minimum confidence selanjutnya.

c. Rule Minimum Support $40 \%$ dan Minimum Confidence 80\%

Untuk rule yang dihasilkan pada minimum support $35 \%$ dan minimum confidence $60 \%$ disini menghasilkan 19 rule dengan lift ratio 1,04 sampai 1,67 hasil ini akan kita bandingkan dengan nilai minimum support dan minimum confidence selanjutnya.

Pada tahap evaluasi ini membuktikan bahwa implementasi algoritma Apriori pada aplikasi yang dibangun dapat digunakan sebagai bahan rekomendasi berupa rule itemset untuk membantu dalam menambah stok obat yang ada dan tata letak obat tersebut pada apotek karunia montong gamang lombok tengah.

Tabel 6 Hasil Perbandingan Rule

\begin{tabular}{|c|c|c|c|c|}
\hline No & Min.Sup & $\begin{array}{c}\text { Min. } \\
\text { Conf }\end{array}$ & $\begin{array}{c}\text { Hasil } \\
\text { Rule }\end{array}$ & Lift Ratio \\
\hline 1. & $30 \%$ & $80 \%$ & 20 & $1-1,25$ \\
\hline 2. & $40 \%$ & $80 \%$ & 10 & $1-1,25$ \\
\hline 3. & $35 \%$ & $60 \%$ & 19 & $1,04-1,67$ \\
\hline
\end{tabular}

\section{SIMPULAN}

Berdasarkan penelitian yang berjudul Penentuan Pola Pembelian Obat dengan Algoritma Apriori, diperoleh beberapa kesimpulan sebagai berikut:

a. Keluaran utama yang dibangun dari program berupa pola itemset yang disertai dengan nilai minimum support, nilai minimum confidence, dan lift ratio dari data transaksi yang telah diproses dengan teknik Asosiasi dan Algoritma Apriori.

b. Program yang dibangun menggunakan transaksi penjualan untuk mengetahui informasi terkait pembuatan itemset antara obat 1 dengan obat lainnya yang akan digunakan sebagai rekomendasi dalam menambah stok obat dan juga tata letak obat berdasarkan rule yang dihasilkan agar nantinya karyawan bisa lebih efisien dalam melakukan pelayanan kepada konsumen. 
c. Program yang dibangun mampu memberikan penjelasan tentang pembentukan 1 itemset sampai 3 itemset dengan hasil yang sebelumnya diambil dari 3 itemset yang lolos untuk dijadikan acuan dalam pembentukan aturan asosiasi agar mendapatkan hasil rule.

\section{DAFTAR PUSTAKA}

Aggarwal, C. C. (2015) Data Mining the Textbook, Springer. doi: 10.1016/0304-3835(81)90152-X.

Efendi, M. I. (2019) 'Penerapan Algoritma Apriori Terhadap Data Penjualan Untuk Mengetahui Pola Pembelian Konsumen " Studi Kasus: Toko Aneka ",, UIN Sunan Kalijaga Yogyakarta.

Gibran, R. and Aripin (2016) 'Analisis Aturan Asosiasi Menggunakan Algoritma Apriori Untuk Menentukan Inventori Apotek', Udinus Repository, (5), p. 7. Available at: https://docplayer.info/47321099-

Analisis-aturan-asosiasimenggunakan-algoritma-aprioriuntuk-menentukan-inventoriapotek.html.

Grand, G. (2018) 'Penerapan Algoritma
Apriori untuk Menemukan

Hubungan Data Murid dengan Nilai Sekolah', Ikraith Informatika, 2(18), pp. 7-12.

Hasan, N. F. et al. (2019) 'Sistem Pendukung Keputusan Penentuan Kombinasi Paket Produk Pertanian Menggunakan Algoritma Apriori', Eksplora Informatika, 9(1), pp. 38-49. doi: 10.30864/eksplora.v9i1.261.

Hasanah, H. (2017) 'Teknik-Teknik Observasi (Sebuah Alternatif Metode Pengumpulan Data Kualitatif Ilmu-ilmu Sosial)', AtTaqaddum, 8(1), p. 21. doi: 10.21580/at.v8i1.1163.

Jayapana, R. D. and Rahayu, Y. (2015) 'Analisis pola pembelian konsumen dengan algoritma apriori pada apotek rahayu jepara', UG Jurnal, Vol. 8, pp. 16.

M. Afdal, M. A. and Rosadi, M. (2019) 'Penerapan Association Rule Mining Untuk Analisis Penempatan Tata Letak Buku Di Perpustakaan Menggunakan Algoritma Apriori', Jurnal Ilmiah Rekayasa dan Manajemen Sistem 
Informasi, 5(1), p. 99. doi: 10.24014/rmsi.v5i1.7379.

Putra, J. L. et al. (2019) 'Implementasi Algoritma Apriori Terhadap Data Penjualan Pada Perusahaan Retail', Jurnal Pilar Nusa Mandiri, 15(1), pp. 85-90. doi: 10.33480/pilar.v15i1.113.

Syahrir, M. and Fatimatuzzahra, F. (2020) 'Association Rule Integrasi Pendekatan Metode Custom Hashing dan Data Partitioning untuk Mempercepat Proses Pencarian Frekuensi Item-set pada Algoritma Apriori', MATRIK: Jurnal Manajemen, Teknik Informatika dan Rekayasa Komputer, 20(1), pp. 149-158. doi: 10.30812/matrik.v20i1.833.

Tiarapuspa et al. (2020) 'Pelatihan industri kreatif di institute kemandirian dompet dhuafa', Indonesian Journal of Economic Community Development, 1(1), pp. 9-17. doi: http://dx.doi.org/10.25105/ijecd.v 1i1.6710. 